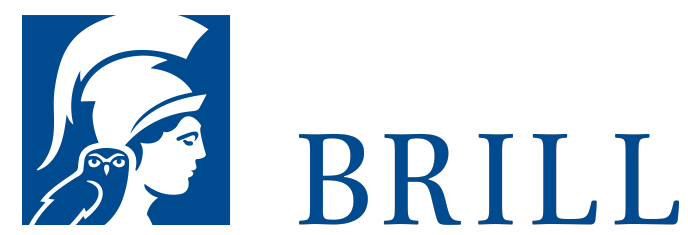

\title{
Im Kopf die Unendlichkeit
}

Fesselung und Entfesselung des Denkens durch Mathematik

Author: Ulrich Nortmann

Zum Nachrechnen: 45 ist gleich $3^{*} 3+6 * 6$. Es handelt sich also bei 45 um eine Zahl, die als Summe von zwei ganzzahligen Quadraten darstellbar ist. Bei der Nummer 242 funktioniert es auch. Geht das immer so, ob ungerade oder gerade, ob kleinere oder größere Zahl? Nein. Nicht jede natürliche Zahl ist in dieser Weise darstellbar. Wie lassen sich dann aber die Fälle charakterisieren, bei denen es geht? Steckt ein Gesetz dahinter? Vielleicht ein Gesetz, das mit den in vieler Hinsicht rätselhaften Primzahlen zu tun hat, aus denen die Zahlen sich wie Moleküle aus Atomen zusammensetzen? Die mathematische Antwort, die man auf solche Fragen, letztlich in der Spur von großen Zahlentheoretikern wie Euler und Gauß, geben kann, wird von Nortmann im Detail nachgezeichnet. Es ist eine Antwort, die ins Gebiet der Primzahl-Theorie für höhere algebraische Zahlkörper weist. Was man aus ihr darüber lernen kann, wie anspruchsvolle Mathematik in charakteristischen Bereichen überhaupt funktioniert, ist die Grundierung für die philosophischerkenntnistheoretischen Teile des Buches. Zugleich liefert der Autor eine farbige wissenschafts- und kulturgeschichtliche Einbettung der Phänomene, und nicht zuletzt: Poesie und Satire sind in diesem sehr persönlichen, autobiographisch geprägten Buch ebenfalls dabei.

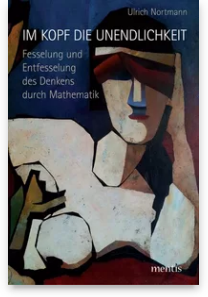

Pages: 422

Seiten

Language:

German

Subjects:

General, Philosophy

Publisher: Brill | mentis

E-Book (PDF)

Released online: 10 Feb 2015

ISBN: 978-3-

95743-984-о

List price

Paperback

Publication date: 10 Feb 2015

ISBN: 978-389785-073-6 List price 
For more information see brill.com

Order information: Order online at brill.com +44330 333 0049 | customerservices@brill.com Submission information: brill.com/authors

Titles published by Brill | Fink, Brill | mentis or Brill | Schöningh: +49(o)715413279216| brill@brocom.de 